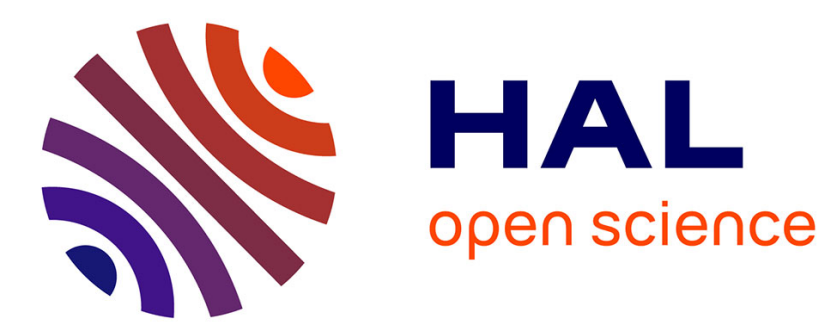

\title{
Human-Machine Systems concepts applied to Control Engineering Education
}

\author{
Pascale Marangé, François Gellot, Bernard Riera
}

\section{To cite this version:}

Pascale Marangé, François Gellot, Bernard Riera. Human-Machine Systems concepts applied to Control Engineering Education. 7th IFAC World Congress (IFAC'08), Jul 2008, Seoul, South Korea. pp.CD. hal-00385501

\section{HAL Id: hal-00385501 https://hal.science/hal-00385501}

Submitted on 19 May 2009

HAL is a multi-disciplinary open access archive for the deposit and dissemination of scientific research documents, whether they are published or not. The documents may come from teaching and research institutions in France or abroad, or from public or private research centers.
L'archive ouverte pluridisciplinaire HAL, est destinée au dépôt et à la diffusion de documents scientifiques de niveau recherche, publiés ou non, émanant des établissements d'enseignement et de recherche français ou étrangers, des laboratoires publics ou privés. 


\title{
Human-Machine Systems concepts applied toControl Engineering Education
}

\author{
Pascale Marangé, François Gellot, Bernard Riera \\ CReSTIC/UFR des Sciences Exactes et Naturelles/ Université de Reims Champagne-Ardenne \\ Moulin de la Housse - BP 1039 - 51687 REIMS Cedex 2 -France \\ \{pascale.marange,francois.gellot, bernard.riera\}@univ-reims.fr
}

\begin{abstract}
In this paper, we interest us to Human-Machine Systems (HMS) concepts applied to Education. It is shown how the HMS framework enables to propose original solution in matter of education in the field of control engineering. We focus on practical courses on control of manufacturing systems. The proposed solution is based on an original use of real and large-scale systems instead of simulation. The main idea is to enable the student, whatever his/her level to control the whole system, from novice to expert, in a safety mode. The teacher is responsible for sharing the control design tasks between the student and the automatic system. Different teachers and students have tested this approach, on different manufacturing systems. By an experiment with a class of "10-year-old novice control engineer", we have shown the interest and the power of the proposed solution. We have proposed at the children to realize their first control program of a packaging process. This experiment encountered a big success.
\end{abstract}

\section{INTRODUCTION}

This paper deals with Human-Machine Systems (HMS) concepts applied to Education. It is shown how the HMS framework enables to propose original solution in matter of education in the field of control engineering. This paper focuses on practical courses on control of manufacturing systems. The HMS approach involves a solution based on an original use of real and large scale systems instead of simulation. The main idea is to enable the student, whatever his/her level to control the whole system, from novice to expert, in a safety mode. The teacher is responsible for sharing the control design tasks between the student and the automatic system. This approach has been successfully tested on different manufacturing systems with different teachers and students. To show the interest and the power of the proposed solution, an experiment with a class of " 10 -year-old novice control engineer" was carried out in order to enable them to realize their first control program of a packaging process. This experiment encountered a big success.

The first part of the paper deals with HMS and automation and the specific concepts and framework behind HMS. The second part of the paper deals with control engineering education. The third part of the paper shows how HMS concepts applied to control engineering education involves an original solution in matter of practical courses. Hence, the last part of the paper presents the original application where children performed the control of a complex process.

\section{HUMAN-MACHINE SYSTEMS AND AUTOMATION}

Why and when to automate? The technical centred approach considers that automation has to be performed when it is possible. Another, the humanist approach, is to automate when the task is boring, physically risky, or otherwise unpleasant and undesirable for a human being. The economist approach is to automate when it is cheaper than human labor. The HMS approach is to consider that automation is not to simply withdraw Human Operator (HO) from the control- command loop (Bainbridge, 1983). This approach implies that automation can vary from different levels (manual to fully automatic) and that in most of the cases; automated systems have to work conjointly with one or several HO. The scientific achievements in HMS comprise contributions in human performance modelling, industrial process control, man's role in HMS, problem solving, human computer interaction, human reliability, human-machine cooperation (Johannsen, 2007)... One of the main originality of HMS is that the approach is much more systemic than analytic (Riera et al., 2003). A new "tool" or "artefact" affects how work is done, but also how it is conceived of and organised. This will have consequences for other parts of work, and may lead to unforeseen changes with either manifest or latent effects. That is particularly true in the context of supervisory control of complex systems.

HMS design adopts principles of systemic approach and leads to original solutions in matter of automation and solutions to support cooperation between $\mathrm{HO}$ and technical systems. Design Support Systems (DSS) are designed to assist HO in order to facilitate their tasks and avoid faulty performances. HMS approach requires having in mind the next points (Riera et al., 2003).

- The main objective is the improvement of the global performance of the HMS (and not only the technical system).

- Consequently, induced effects of the artefact have to be taken into account. For that, the HMS is studied, taking into account as well human characteristics (necessity of human decisional models) as technical aspects.

- An evaluation stage is necessary even if it is difficult to perform because the HO's cognitive behaviour is not directly observable.

HMS involves original dynamic system design close to systemic concepts. A comparison made by de Rosnay of analytic and systemic approaches is proposed Table 1, (Rosnay, 1975). The systemic approach is the application of 
the concept of system to solve problems.

Table 1. Analytic vs Systemic approach

\begin{tabular}{|c|c|}
\hline Analytic approach & Systemic approach \\
\hline Concentrate on the elements & $\begin{array}{c}\text { Concentrate on interactions } \\
\text { between elements }\end{array}$ \\
\hline Consider the nature of interactions & $\begin{array}{c}\text { Consider the effects of } \\
\text { interactions }\end{array}$ \\
\hline Consider the precision of details & Consider the global perception \\
\hline $\begin{array}{c}\text { Precise models but difficulty to } \\
\text { use them in actions }\end{array}$ & $\begin{array}{c}\text { Models not enough rigorous but } \\
\text { easy to use }\end{array}$ \\
\hline Deal to a planned action & Deal to an action by objectives \\
\hline $\begin{array}{c}\text { Knowledge of details, goals not } \\
\text { well defined }\end{array}$ & $\begin{array}{c}\text { Knowledge of goals, details not } \\
\text { well defined }\end{array}$ \\
\hline
\end{tabular}

HMS approach is systemic oriented because it considers automation as integrating $\mathrm{HO}$, and studying particularly interactions between human being and the technical system. Consequently, for instance, design of supervisory tools and particularly human machine interfaces require process analysis, cognitive models, and choice of function allocation between human and machines. HMS approach has conduced two alternatives to technical centred approaches for automation. Dynamic Tasks Allocation (DTA) and HumanMachine Cooperation (Millot, 1998) are examples of original solutions proposed and evaluated by "human centred engineers". In the first case, the idea is to adapt the level of automation to the task demands and HO's workload in order to optimize HMS performance. In the second case, HMS can be defined through the three forms of cooperation defined by Schmidt, (Schmidt, 1991):

- Augmentative cooperation: Cooperation is augmentative when human and machines have a similar know-how but the agents must be multiplied to perform a task too demanding for only one agent. The task is shared into similar sub-tasks.

- Integrative cooperation: Cooperation is integrative when human and machines have different and complementary know-how and it is necessary to integrate their contribution for achieving a task.

- Debative cooperation: Cooperation is debative when human and machines have a similar know-how and are faced with a unique task, and they compare their results for obtaining the best solution.

For Grislin and Millot, any cooperation situation may be described as a combination of these three forms (Grislin and Millot, 1999). The choice of the cooperation depends on and influences the level of automation and the HO's tasks.

The following paragraph deals with control engineering education.

\section{CONTROL ENGINEERING EDUCATION}

Control engineering courses as all technical courses in the broad sense require the transfer of knowing and know-how to learners. Usually, courses are divided into theoretical courses, exercises, and practices. In this paper, we focus on the control of manufacturing systems. In this field, courses concern the study, at different levels, of states automata, combinatory and sequential logics, Statecharts, Petri nets, Grafcet, SFC (Sequential Function Chart) whose developments are still in progress (Golmakani et al., 2006), (Polic and Jezernik , 2005). The level of knowledge is linked to the teaching level varying from discovery to specialization. Know-how concerns, for instance, the use and the programming of Programmable Logic Controllers (PLC) by means of software respecting standard like IEC 1131.3 (IEC, 1991). However, the manufacturing system is a part of a factory system where components are in interaction. This interaction becomes more and more important due to the use of Communication and Information Technologies which is a reality in the automation field. Indeed, one can find a massive use of the Ethernet network, as well as the level of the inputs/outputs (sensors and actuators), as in the communication between PLC. The use of TCP-IP, Web server in the PLC is to send Email or to connect to data bases like Oracle, Sql server or My SQL are classical applications. Thus, remote access to the controller via Internet has become a reality, allowing for example PLC programming, supervisory control and plant maintenance and tele-operation (Sim et al., 2006).

The acquisition of this technical know-how requires practical work using either plant simulation or "real" plant.

In the following paragraph, we see how HMS concepts can be applied to control engineering education in order to propose an original solution to practical courses.

\section{HMS CONCEPTS APPLIED TO CONTROL ENGINEERING EDUCATION}

We do not develop the classical approach from education sciences based on specific models. Practical courses from HMS point of view conduce to study a HMS composed of 2 humans: student and teacher and 1 artefact having to be controlled. Applying the HMS/systemic view by concentrating on Humans-Machine interaction involves the following three points about the specifications:

- To keep a global perception of the system for students. This important point aims at always considering the system having to be controlled as a whole.

- To allow making errors and learning from errors (Boy, 1996) and to supply explanations. This requires to design specific control validation tools.

- The controlled system must be adapted to the teacher's objectives which are linked to the learner's level. This means that at the end, the student's control tasks have to be adaptative.

To take into account these three specifications, we propose the three following answers.

\subsection{To work on real and large size systems}

Real and large systems are close to the "real world" and composed of several inputs/outputs. These systems can be decomposed in several sub-systems and have a certain level of complexity. In addition, these systems are also able to perform several functions. The main idea coming from the HMS framework is to give the possibility for the student, whatever his/her level, to use it as a whole. It seems much more pertinent and interesting for students to work on the complete system than on a simple part. This point is going to be developed in the following of the paper.

\subsection{Control Validation}

Student can make mistakes during the control design stage. 
These errors can be classified as following: syntaxical errors and specification errors. We are not interested in syntaxical errors because they will be detected during the programming stage by the PLC software. Specification errors can have different consequences on the plant. For instance, an error can involve the plant either to a state which does not correspond to the specification or to a forbidden state which is very dangerous. Necessary, errors come from a "Bad" command sent by the PLC. "Bad" means in this case, not adapted to the context of the production system. Experiencing errors is enriching and are good for contextualizing learning (Boy, 1996). Of course, it is necessary to give the tools to student to understand the effects and the causes of the error without causing breakdowns. For that, it is necessary to implement a control validation module. Work in the field of automatic control validation aims to certify that mathematical properties are respected by the control model (Pollmacher et al., 2005), (Lamperière and Lesage, 2000). The work undertaken within the framework of tool UPPAAL (Behramm et al., 2004) defines three types of properties: attainability, safety and liveness. In this paper, we only consider "safety constraints": it is to say what the system should not do. This approach is complementary to those used in process supervision and fault diagnosis where the process state is compared to a dynamic model of the process (Lo et al., 2006). Our work is oriented to an on-line approach of control validation, based on a validation filter established directly in the PLC. By this approach of validation, the idea is to inhibit the evolutions which can lead the system to a situation of risk for operators and production resources.

\subsection{Adaptative student's control}

It is obvious that a control problem must be adapted to the learner's level. The analysis level, knowledge and competence required are not the same for a student who discovers the automation field and for a student who follows a specialization course. However, whatever the level, to work on a real system is much more motivating for a learner.

It is relevant to the teacher to define an exercise adapted to learner. It is necessary to define the concept of "difficulty" which is quite close to the concept of "complexity". The characteristics of a "complex system" are: the high number and the large variety of variables, the big quantity of information, the significant number of subsystems, the interconnection between the subsystems... The perception of the system complexity, its analysis and its modelling are specific to the observer's objectives and his investigation and observation. Morten Lind (Lind, 1994) in a HMS/systemic approach considers that the systems can be broken up according to 2 axes called "Means-Ends" and "Whole-Part". By the distinction between means and ends, a system is, for Lind, described in terms of goals, functions and the physical components. At the same time, each of these descriptions can be given on different levels of "Whole-Part" decompositions. We use this perception of a system in our context. The level of difficulty of the specification of a control problem, from our point of view, depends on three interdependent control parameters: the dimension, the hierarchization, and the synchronization (Marange et al., 2007).

The control dimension is directly related to the number of subsets having to be controlled. It depends on the low decomposition level on the sensors and actuators number necessary to design the control described by the running specification. If the granularity is important, more the analysis effort is strong for student and more the difficulty level is higher. It seems to us that if student is expert, he is able to work on the low level of the axis "Means-Ends", i.e. on the sensors-actuators level. The management of a "normal" cycle without taking account of the various operation modes requires a simple sequential control. On the other hand, a "complete" running specification integrating various operation modes and emergency stop requires a solution of hierarchical control. The specification stage is then more difficult. In practice, hierarchization appears through the forcing instructions of PLC control for example. The two preceding parameters reveal synchronizations due to the definition of the system dimension (simultaneous evolution of events) and to the hierarchization generated by some priorities between the various operating modes. However, the control problems can also require some particular synchronization structures of events management or common space.

The teacher can modulate the difficulty level of a logic control design by modifying either dimension, or synchronization, or structuration degrees through the control problem specifications. The 3 parameters are not independent to each other. For instance the choice of the inputs/outputs $(E / S)$ makes possible to decrease the degrees of synchronization and hierarchization. The HMS framework deals to another way to adapt the difficulty level.

The idea, that we develop, is to adapt the difficulty level by modifying specifications at the "functional" level of the "Means-Ends" axis. Hence by modifying the automation degree, it becomes possible to keep a global vision of the system. For that, we propose to adapt the difficulty level by using the functional dimension of the controller, and the autonomy given to the learner. These two aspects will make it possible to modify the automation degree. The idea is to limit the perception of the plant and the possibilities of actions of the student. In other words, the student has to design a logic controller using advanced inputs/outputs called respectively AE1, AS1. To choose "the new" plant dimension requires for the teacher to define the inputs/outputs. This work can be performed through a functional analysis of the system. We have proposed (Marange et al, 2007) the following representation of the functions (figure 1). A function characterizes a sequence which can be more or less complex. A function thus integrates a degree of synchronization and structuration.

A function is activated by the mean of a request for activation (RA) and is deactivated by the mean of a request for deactivation (RD). The effective engaging of the function can be made only if the activation conditions (Cai) are present. In the same way, the function deactivation is effective if the deactivation conditions (Cdi) are present. Fil characterizes the effective operation of the function. Fi2 represents the time between an activation request and a deactivation request. The function can be in autonomous mode or not. In the first case, the activation and the deactivation of the function will be done automatically when the activation and deactivation conditions are respectively true. In the contrary case, the learner has to 
activate or to deactivate the function at the right moment when the conditions are fulfilled. In this case, alarms (dsi, fsi) are set if the request does not coincide temporally with the conditions.

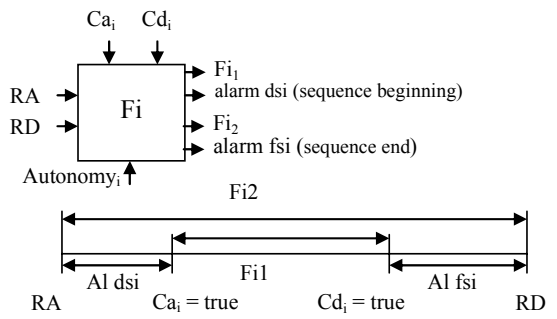

Fig. 1. Function concept

From Human Machine Cooperation point of view, 2 forms are present in the proposed solution.

- Augmentative cooperation: teacher can decide to share the control tasks between the student and the controller. For instance, the student should have to manage the station 1 and the station 2 is autonomous.

- Integrative cooperation: some control parts are too complex with regard to the student's level. The functional approach proposed enables this kind of cooperation.

Figure 2 presents the principle and the implementation of the solution. An on-line validation approach by filter is taken up partially and adapted to ensure the control validation. The approach is based on two filters. A first "system validation filter" is at the plant level i.e. for each new evolution of outputs S (actuators), the filter verifies that these one are compatible with the plant state perceived by means of inputs E (sensors). However, the learner controls the plant with AE1 and AS1 placed at his disposal. A second "functional validation filter" makes it possible to valid coherence between the outputs AS1 and inputs AE1, and can generate alarms if the "autonomous" mode isn't selected. Only the "system validation filter" authorizes or not the sending of the $\mathrm{S}$ to the plant. If the order is validated by the filter, it is sent to the system, if not the system is stopped and the learner is informed. The functional validation filter reduces and defines the possible control errors coming from the student. It is also useful to supply explanations concerning the error, but it is the sensors/actuators validation filter that guarantees the system safety. The 2 filters are placed in the PLC. It is necessary in addition to the 2 filters, to program the various functions in the PLC and the rebuilt information (AE1/AS1) (Observer/estimator). In this paper, the filters and the way to build them are not described.

The solution has been implemented on specific machines at Reims Champagne-Ardenne University and enables students from beginners to experts to use them in a safety way. To prove the modularity and the interest of the solution, we have performed an original evaluation with young novice control engineers. This work is now presented.

\section{ORIGINAL APPLICATION WITH «NOVICE CONTROL ENGINEERS »}

The idea, in order to test the approach, was to propose to "novice control engineers", in their case 10-year-old children, to design their first logic control program to control the PRODUCTIS system. For that, we collaborated with a teacher of primary school.

\subsection{Definition of system}

At Reims Champagne-Ardenne University, an automation system called PRODUCTIS is available. PRODUCTIS is an Integrated Manufacturing System which hinges around a pallet-based free transfer system as used in an industrial environment (Figure 3). It has been designed to bottle-pack medicine tablets. The system includes:

- Two reference automatic subassemblies (small or large bottle) which distribute the tablets (white and green) through counting close the bottle with a stopper and evacuate bottle,

- Two equivalent removable automatic subassemblies (concept of subsystem) making it possible to carry out maintenance operations (disassembly/refitting, adjustment) in production conditions.

They have been designed to allow series changes (tools suited to two types of bottles and stoppers).

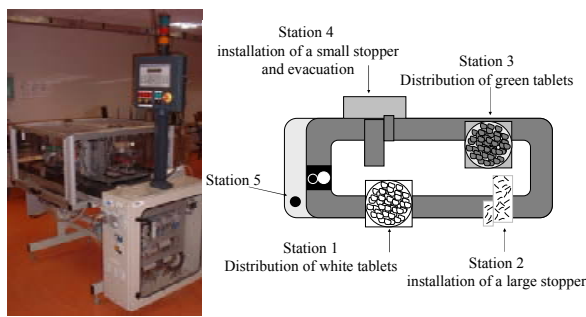

Fig. 3. Productis

The process has been designed to carry out the following steps: Manual loading of the pallet (bottle/stopper) (station 5), Product batching through tablet counting (station 1-3), Bottle closing (station 2-4), and Bottle evacuation (station 4). This system is composed of two PLC, with 68 inputs and 33 outputs.

\subsection{Definition of difficulty level}

With regard to the age and level of the young control engineers, it was decided to decrease the level of difficulty at high rate. For that:

- Autonomous mode has been selected,

- Component and functional dimensions have been reduced in order to decrease the numbers of inputs and to avoid control synchronization. In other words, the control program, for the children, is a cycle of a single sequence of functions.

- Only one function of the PRODUCTIS system can be active when a bottle is manufactured.

After functional identification of the system, we selected 20 functions (Table 2) that could be programmed by children. For that, they analysed the system by stations. The pallet is manually loaded (station 5). The child presses on a button to release the pallet. Each station is analysed here. 


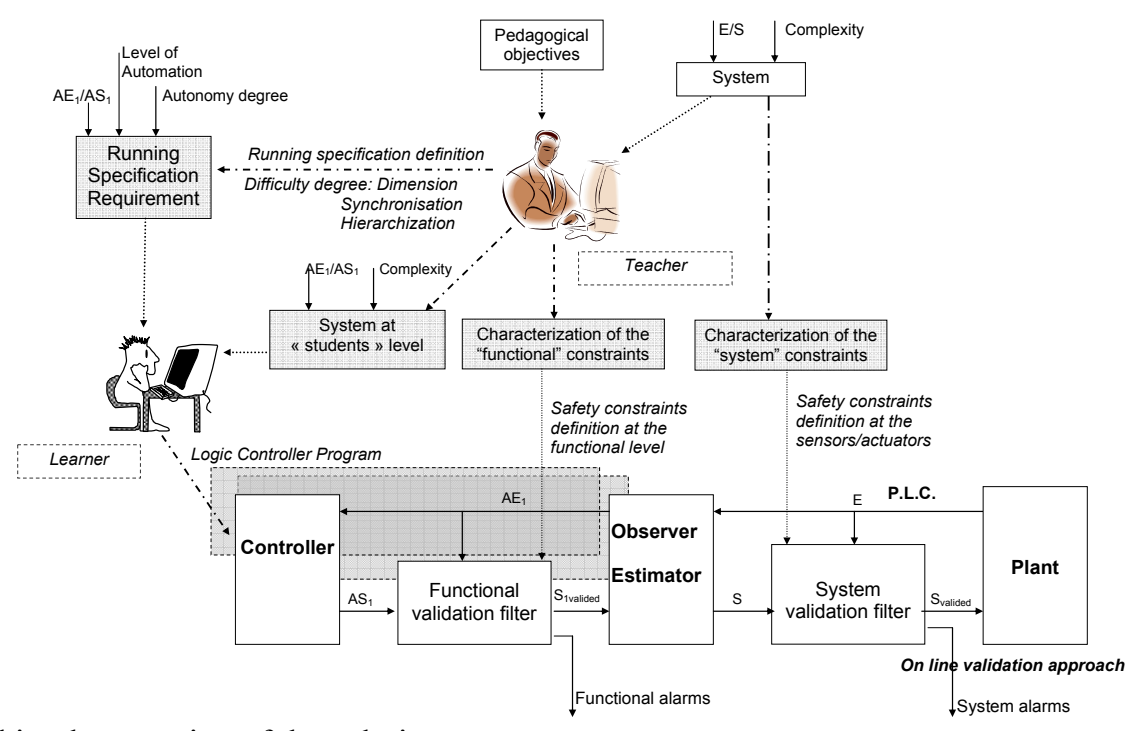

Fig. 2. Principle and implementation of the solution

- Station 1: Distribution of green tablets and Station 3: Distribution of white tablets. Stations 1 and 3 performed two functions each other (F11, F31: distribute a tablet and F12, F32: release the pallet to go to the following station). The sequences generated by F11 and F31 are quite complex (backward sequence skip + selection of sequences). However, the modification of the functional dimension has completely withdrawn the complexity. Children control the distribution only by the mean of the output F11 and F31,

- Station 2: positioning of large stopper and Station 4: positioning of a small stopper and evacuation. This station is composed of a prehensor, i.e. two cylinders (one for the vertical movement and one for the horizontal movement), and a vacuum system. To install a stopper, it is necessary to place the cylinder to the top, go down, take the cap, go up, advance the cylinder, go down and release the aspiration. The functional identification is described at the lower level using the functions F21, F22, F23, F24, F41, F42, F43 and F44. In order to avoid synchronization in the control program designed by children, functions F25 and F45 (put the stopper) have been divided into two functions respectively: Take (F251 and F451) and Loosen (F252 and F452). With regard to the functional analysis, children also have to program the control of the ejection by means of the gripper (station 4) Through a FMEA, it has been decided that control errors would only be a bad activation of functions related to stations 2 and 4 . For the 20 selected functions, activation $(\mathrm{Ca})$ and deactivation $(\mathrm{Cd})$ conditions can be found in Table 2 .

\subsection{Activity with children}

The activity with the children proceeds in two steps. In the first, the child has at his/her disposal an HMI (HumanMachine-Interface) with 20 command buttons. The 20 buttons represent the 20 functions of the PRODUCTIS. In this activity, the child has to understand the function behind each button. For that, the child clicks a button and the associated function starts. According to the state of the system, all the buttons are not activated. For example, if the cylinder of station 2 is in position "in2", the button "To Go in the cylinder" of station 2 cannot be clicked (no entry sign on the button). This button is inactive until the cylinder is in the position "out". After having understood the function behind each button, the child can perform the second part of work

\begin{tabular}{|c|c|c|c|c|c|c|c|c|}
\hline \multicolumn{5}{|c|}{ Functional Identification } & \multirow{2}{*}{$\mathrm{Ca}$} & \multirow{2}{*}{$\mathrm{Cd}$} & \multirow{2}{*}{ S1 } & \multirow{2}{*}{ S: PLC variables } \\
\hline Level 0 & Level 1 & \multicolumn{2}{|c|}{ Level 2} & Level 3 & & & & \\
\hline \multirow{20}{*}{$\begin{array}{l}\text { Packaging } \\
\text { of tablets }\end{array}$} & \multirow{3}{*}{$\begin{array}{c}\mathrm{P}_{1} \text { : Distribute green } \\
\text { tablets, } \\
\text { P3 : Distribute } \\
\text { white tablets } \\
\end{array}$} & \multirow{2}{*}{\multicolumn{2}{|c|}{$\mathrm{F}_{11(31)}$ : Distribute a green tablet $(1)$}} & & \multirow{2}{*}{ pallet in station 1(3) } & \multirow{2}{*}{ tablet1(3) } & \multirow{2}{*}{ F11 } & Turn1+:\%Q2.18 \\
\hline & & & & & & & & Turn1-: \%Q2.19 \\
\hline & & $\mathrm{F}_{12(, 32)}$ : Release & pallet to station1 (2) & & pallet in station $1(3)$ & /pallet in station1(3) & $\mathrm{F} 12$ & Release1:\%Q2.16 \\
\hline & \multirow{8}{*}{$\begin{array}{c}\mathrm{P}_{2}: \text { Close a large } \\
\text { bottle }\end{array}$} & $\mathrm{F}_{21}: \mathrm{Go}$ & cylinder2 (3) & & 1 & out 2 & F21 & Go_out2 : \%Q2.22 \\
\hline & & $\mathrm{F}_{22}$ : Go & cylinder2 (4) & & 1 & in 2 & F22 & Go_in2: \%Q2.23 \\
\hline & & $\mathrm{F}_{23}$ : Go & cylinder2 (5) & & 1 & up2 & F23 & Go up2: \%Q2.21 \\
\hline & & $\mathrm{F}_{24}:$ Go d & $\mathrm{n}$ cylinder2 (6) & & 1 & down2 & $\mathrm{F} 24$ & Go_down2 : \%Q2.21 \\
\hline & & \multirow{4}{*}{\multicolumn{2}{|c|}{$\mathrm{F}_{25}:$ Put the large stopper }} & $\mathrm{F}_{251}:$ Take2 (7) & 1 & $\uparrow F_{252-1}$ & F251 & Aspire2 : \%Q2.48 \\
\hline & & & & $F_{55_{2}}:$ Loosen $2(8)$ & 1 & $\varnothing$ & $\mathrm{F} 252$ & Aspire2 : \%Q2.48 \\
\hline & & & & & & & & Eject2 : \%Q2.49 \\
\hline & & & & & pallet in station 2 & /pallet in station2 & F26 & Release2 : \%Q2.17 \\
\hline & \multirow{9}{*}{$\begin{array}{c}\mathrm{P}_{4} \text { : Close a small } \\
\text { bottle or/and } \\
\text { evacuate bottle }\end{array}$} & \multirow{6}{*}{$\begin{array}{c}\mathrm{F}_{40} \text { : Close the small } \\
\text { bottle }\end{array}$} & $\mathrm{F}_{41}$ : Go out cylinder 4 (12) & & 1 & out 4 & F41 & Go_out4 : \%Q2.38 \\
\hline & & & $F_{42}:$ Go in cylinder 4 (13) & & 1 & in 4 & $\mathrm{~F} 42$ & Go_in $4: \%$ Q2.39 \\
\hline & & & $\mathrm{F}_{43}:$ Go up cylinder 4 (14) & & 1 & up4 & F43 & Go up $4: \%$ Q2.37 \\
\hline & & & $\mathrm{F}_{44}:$ Go down cylinder 4 (15) & \multirow[b]{2}{*}{$\mathrm{F}_{451}:$ Take4 (16) } & 1 & down4 & F44 & Go_down $4: \%$ Q2.36 \\
\hline & & & \multirow[b]{2}{*}{$\mathrm{F}_{45}:$ Put the small stopper } & & 1 & $\uparrow_{452-1}$ & F451 & Aspire4 :\%Q2.50 \\
\hline & & & & $\mathrm{F}_{452}:$ Loosen $4(17)$ & 1 & $\varnothing$ & F452 & Aspire4:\%Q2.50 \\
\hline & & \multirow{2}{*}{$\mathrm{F}_{46}$ : evacuate the bottle } & $\mathrm{F}_{47}:$ Open the gripper $(18)$ & & 1 & $\varnothing$ & F47 & $\frac{\text { Eject } 4: \% Q 2.51}{\text { Open : } \% \text { Q2.25 }}$ \\
\hline & & & $\mathrm{F}_{48}:$ Close the gripper (19) & & 1 & $\varnothing$ & $\mathrm{F} 48$ & Close: $\% \mathrm{Q} 2,24$ \\
\hline & & \multicolumn{2}{|c|}{$\mathrm{F}_{49}$ : Release the pallet to station $4(20)$} & & pallet in station 4 & pallet in station 4 & F49 & Release 4:\%Q2,33 \\
\hline
\end{tabular}

Table 2: functional identification of Productis machine 
(second HMI). During the second activity, the child programs his own sequence of functions to bottle medicine tablets through a specific Human-Machine Interface. When the sequence is considered as correct by the child, it is sent to the PLC and the sequence execution is validated on line. The running of the PRODUCTIS system is displayed on a multimodal interface (Marin et al., 2005). When the safety constraints are respected, sequence runs normally. If a safety constraint is violated, the child is informed with an explanatory alarm and the PRODUCTIS is stopped and returns to its initial position. To ensure the children and system safety, we have defined the following constraints:

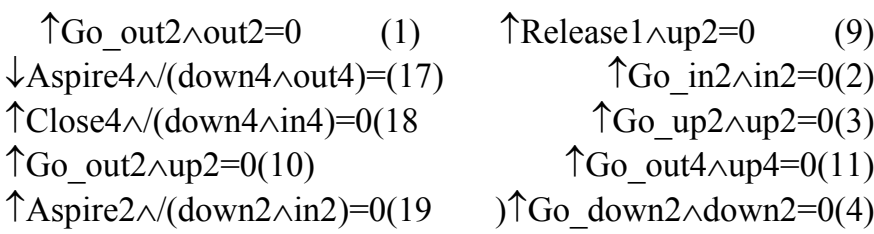

$\uparrow$ Release $2 \wedge$ up $2=0(12) \downarrow$ Aspire $2 \wedge /($ down $2 \wedge$ out 2$)=0(20), \ldots$

Let them suppose that the child proposes the following sequence $\left(F_{12} \rightarrow F_{24} \rightarrow F_{251} \rightarrow F_{21} \rightarrow F_{252}\right)$ knowing that there is a pallet at station 1 , the cylinder of station 2 is in "up and in" position ( $u p 2=1, \operatorname{in} 2=1$ ) and the vacuum is not active (Loosen 2 $=0$ ). During the sequence execution, the function F12 generates the output Release1 (\%Q2.16) and the constraints set is respected. The output is then sent to the system which effectively releases the pallet at station 1 . It is the same for the functions F24 and F251, which generates outputs: Go down 2 and Loosen 2 . The control error comes when the function F21 is activated. In this case, the output Go_out 2 becomes equal to 1 and the constraint (10) is not validated. So, the PRODUCTIS is stopped and the validation system informs the child of his error. Afterwards, he/she must modify his/her control sequence and he/she starts the system to validate it again. This activity has had a great success and most of the children performed the control programming task in less than 2 hours.

\section{CONCLUSIONS}

HMS community is at the intersection of automatic control, cognitive engineering, and human computer interactions communities. The specificity comes from the fact to take into account the human, the system, its control and the interactions. We show in this paper how this approach can also lead to an original solution in matter of control engineering education.

\section{REFERENCES}

Bainbridge L., "Ironies of automation", Automatica, vol 19, $\mathrm{N}^{\circ} 6$, pp.775-779, 1983

Behramm G., David A., Larsen K.G., "A tutorial on UPPAAL", In proceedings of the 4th International School on Formal Methods for the Design of Computer, Communication, and Software Systems 2004

Boy G., "Learning evolution and software agents emergence", Proceedings of ITS, Lecture Notes in Computer Science Series, Berlin, 1996.

Grislin E., Millot P., "Specifying artificial cooperative agents though a systhesis of several models of cooperation", Seven European Conference on Cognitive Science Approaches to Process Control, p.73-78, Villeneuve
d'Ascq, September 1999

Golmakani H., Mills J., Benhabib B., "Deadlock-free scheduling of flexible manufacturing workcells using automata theory", IEEE trans. on systems man and cybernetics, vol. 36, $\mathrm{n}^{\circ} 2$, p.327 - 337, march 2006

International Electrotechnical Commission, "Preparation of function charts for control systems, International Standard", CEI/IEC 848, 1991 (revised version).

Johannsen G., "25 years of Human-Machine Systems in IFAC", $10^{\text {th }}$ IFAC/IFIP/IFORS/IEA Symposium on analysis, Design, and Evaluation of human-Machine Systems, Seoul, September 2007

Lampérière S., Lesage J.J, "Formal verification of the sequential part of PLC programs", Proc. Of 5th IFAC Wodes, pp 247-254, Ghent, Belgium, August 2000

Lind, M., "Modeling Goals and Functions of Complex Industrial Plant. Applied Artificial Intelligence", Vol8 No.2,April-June 1994

Lo, C. H., Wong, Y.K. and Rad, A.B, “An Intelligent System for Process Supervision and Fault Diagnosis in Dynamic Physical Systems", IEEE Trans. on Indus. Elect., Vol. 53 (2), April 2006, pp. 581-592, 2006.

Marangé P., Gellot F., Riera B., "Synthesis of safety system for discrete event control", 4th international conference on informatics in control, automation and robotics Icinco'07, Angers, mai 2007

Marin, R.; Sanz, P.J.; Nebot, P.; Wirz, R., "A multimodal interface to control a robot arm via the web: a case study on remote programming", IEEE Trans. on Indus. Elect., Vol.52, Iss.6, Pages: 1506- 1520, Dec. 2005.

Millot, P., Lemoine, M.P., "An attempt for generic concepts toward human-machine cooperation", IEEE International Conference on Systems, Man, and Cybernetics, Volume: 1, p.1044-1049, 11-14 Oct 1998

Polic A., Jezernik K., "Closed-loop Matrix based of discrete event system for machine logic control design", IEEE Trans. on Indus. Infor.,vol.1(1), p.39-46, February 2005

Pollmacher D.; Zimmermann W.; Hanisch H.-M, "Translation validation for model-based code-generators for PLCs."; Emerging Technologies and Factory Automation, 10th IEEE Conference on Volume 1, Page(s):8 pp. 19-22 Sept. 2005

Riera B, Debernard S, "Basic cognitive principles applied to the design of advanced supervisory systems for process control", Handbook of cognitive task design, Chapter 12, Ed. Erik Hollnagel, p.255-281, Lawrence Erlbaum Associates Inc., 2003

Rosnay J., "Le macroscope: vers une vision globale", Seuil (Eds), Paris, 1975

Schmidt K., "Cooperative work: a conceptual framework", In J. Rasmussen, B. Brehmer, \& J. Laplat (Eds), Distributed Decision-Marking: Cognitive Models for Cooperative Work, p.75-110, Chichester, UK : John Willey and Sons, 1991

Sim K.B., Byun K.S., Harashima F., "Internet based teleoperation of intelligent robot with optimal 2 layer fuzzy controller", IEEE Trans. on Indus. Elec.,vol. 53, Issue 4, p.1362 - 1372 June 2006 